\title{
Finding a vocabulary for the extrascientific significance of technology
}

\author{
Edward S. Golub
}

In a recent commentary (Nature Biotechnology 15:112, 1997), I raised the question of the importance of the extrascientific aspects of science to society. Shortly after that article appeared, Dolly, the cloned sheep, became the topic of newspaper headlines, radio commentaries, cover stories in national news magazines, and barroom discussions. It surely has not escaped the attention of the readers of this journal, both scientists and entrepreneurs, that the public is not bowled over by the technological wizardry that led to Dolly; rather, it is riveted by the social implications of a single question: "Does this mean that humans can be cloned?"

The US National Institutes of Health's, Harold Varmus was correct in advising the US Congress that no restrictive legislation on research is necessary because, from a technical point of view, we cannot at this time define any social harm of the use of the technology. The fascinating aspect is that, despite the predictable talk of cloned animals as production units for drugs or experimental models of disease, there is no social benefit commensurate with the enormous hoopla.

In contrast to such highly visible displays of technological wizardry as the first atomic blast or landing a man on the moon, the declared advantages of the cloning of Dolly seem pallid, and the public gives no indication that it sees any imperative in this act of bravura. From the point of view of the readers of this journal, I think Dolly's most important and immediate significance is that it appears that she was cloned because she could be cloned. This introduces a whole range of profound, nontechnical questions into the public discourse that science is unprepared to deal with.

If we are to deal with these extrascientific questions, Dolly must be viewed in the larger context of biotechnology. Long before Dolly, the public had concerns about the possibility that new genetic tests might reveal traits and susceptibilities that could cause an individual to lose insurance or employment. Many now realize that issues about genetic privacy, while of enormous importance, are qualitatively not

Edward S. Golub, former professor of biology at Purdue University, and director of research at Ortho Biotech, is at the Pacific Center for Ethics and Applied Biology (egolub@esga.com). He is also the author of The Limits of Medicine: How Science Shapes Our Hope for the Cure, University of Chicago Press. very different from the great array of other information about our personal affairs and health that are kept in government and industrial databases, and that the dissemination of genetic information raises issues that are negotiated through the legislative and regulatory processes of free democracies. Given public awareness of the problem, medical information will eventually be as well protected as all

\section{Public discomfort about} genetic information, and now the cloning of Dolly is, of a more profound kind that deals, not with what someone else knows about us, but what we know about ourselves; not with what scientists can tell us about the technology, but what they cannot tell us about its nontechnical effects.

of the other information about us-for whatever comfort that gives. However, these kinds of questions are only one part of the concern.

Public discomfort about genetic information, and now the cloning of Dolly is, of a more profound kind that deals, not with what someone else knows about us, but what we know about ourselves; not with what scientists can tell us about the technology, but what they cannot tell us about its nontechnical effects. These issues cannot be legislated because they are about the existential meaning of the technology; in the case of genetics, what a person sees as their genetically encoded destiny.

The fact that geneticists could-and would-produce Dolly, has brought to public consciousness the fundamental issue of the delicate balance between the hope for cures and fear of the power of geneticists to affect deeply held beliefs that have until now been assumed to be out of the realm of science. To a great many people, the leap from the cloning of a sheep to more direct manipulation of what was thought to be un-manipulatable, has been made. Because they are extrascientific, the concerns raised can only be discussed in a vocabulary that is alien to scientists.

If the promise of biotechnology is fulfilled, we are told that we will each carry an identity card into which is embedded our entire genetic constitution. How can the public deal with the fact that the scientists who see this future as desirable are the same scientists who have promised that all 'bad genes' will be eliminated from the population, and have now cloned a mammal! The prospect that each of us will be forced to confront the terror of our predetermined, innermost selves-to constantly redefine the meaning of normal-is understandably chilling.

To a great extent, biotechnology itself bears much of the blame for this situation. Little effort has been made to distinguish between a gene defining the probability of expression of a trait and the absolute determination of a biological fate. Under the ceaseless barrage of announcements of the identification of genes for rare, monogenic pathological conditions, to polygenic conditions such as atherosclerosis and manic-depressive disease, the public has come to accept the idea that their destiny is in their genes. Assurances from scientists that, in fact, a clone would not be identical to the person from which it is derived because environment plays a large role in development and behavior may be too little, too late: Dolly has brought to the fore the genetic determinism the public has lived with since the inception of the Human Genome Project.

It is very difficult to put genies back into their bottles. Until Dolly, concerns about biotechnology had to do largely with issues that can be discussed because they are voiceable within the framework and language of technology and the law. After Dolly, concerns will move to those that are unvoiceable because we have neither the framework nor the language for them. As scientists we have created such a divide between the world of the technological and the world of the philosophical that any misgivings about technology are attributed to the forces of ignorance and superstition. If we are lucky, Dolly will forces us to take the extratechnical aspects of science seriously.

The public will never be able to evaluate the technical side of science, and relies on the authority and trustworthiness of scientists; mere disclaimers that we are not promoting an absolute genetic determinism will not suffice to allay the unvoicable fear that scientists are not in control of the technology they have spawned, and are no longer to be trusted. III 